\title{
The Difference of Melanin Index in Treatment of MelasmaUsing Non-Hydroquinone Cream and Kligman's Formula
}

\author{
Prasetyadi Mawardi*, Mardiana \\ Department of Dermatology \& Venereology, Faculty of Medicine, SebelasMaret University/Dr. Moewardi General Hospital, Surakarta \\ Indonesia
}

Received: June 02, 2020; Accepted: June 17, 2020; Published: June 23, 2020

*Corresponding author: Prasetyadi Mawardi, Department of Dermatology \& Venereology, Faculty of Medicine, SebelasMaret University/ Dr. Moewardi General Hospital, Surakarta Indonesia, E-mail: prasetyadimawardi@yahoo.com; prasetyadi_m@staff.uns.ac.id

\begin{abstract}
Introduction: Melasma is a hyperpigmented lesion that occurs on different skin areas that are often exposed to sunlight with predilection arising on the face, neck, and partially on arms or other body parts. It is also known as chloasma or black colour. This pigmentation disorder is common to people with IV-VI type of skin, and those living in the environment with more Ultraviolet (UV) exposure. Yet, its etiology has not been understood clearly. The major influential factors on its pathogenesis are UV radiation exposure, endocrine factor, genetic predisposition, the phototoxic/ photoallergies medicine,anticonvulsant medicine,particularly cosmetics, and nutrition deficiency are reportedly less influential or a rare factor. The aim of this research is to prove the difference between melanin index number on melasma patients having therapies by using non-hydoquinone cream and Kligman's formula.
\end{abstract}

Materials and Methods: This is an experimental study, in which a cross-sectional with randomized control study was conducted at Dr. Moewardi General Hospital from June to August 2019. Subsequently, the patients were grouped based on age, occupation, education, and melasma type. The melanin index measurement uses Mexameter ${ }^{\circledR}$ MX-18 (CourageKhazaka), and for accuracy Melasma Area and Severity Index (MASI) score is used. The comparative test was conducted based on Mann-Whitney's statistical analysis, when the data distribution was irregular.The cream combination used in the experiment includes phenylethyl-resorcinol $0.1 \%$, lactic acid $0.04 \%$, palmitol tripeptide- $50.01 \%$, and retinol $0.01 \%$ as non-hydroquinone cream andmodified Kligman's formula (hydroquinone $2 \%$, tretinoin 0,05\%, dexamethasone $0.1 \%$ ) as control.

Results: The experiment was carried out on 32 melasma patients with 18 on the experimental group, and 14 on the control group. However, no significant difference was found between the experimental group (non-hydroquinone treatment) and control group (Kligman's formula) according to age, occupation, education, and melasma patients $(p>0.05)$. Meanwhile, according to the melanin index, there was a significant difference found between the experimental group (non-hydroquinone cream) and control group (Kligman's formula) on the 5th to 8th week visits with $\mathrm{p}=0.04$. However, there was no significant difference according to MASI score on both groups $(p>0.05)$.

Conclusion: A significant difference was found on melanin index's measurements on the 8th week of visit between the non-hydroquinone group and the Kligman's formula group, however, according to MASI score, no significant difference was found on both groups.

Keywords : Melanin index; Non-hydroquinone Cream; Therapy of Melasma

\section{Introduction}

Melasma is a common hyperpigmentation disorder affecting a significant population, especially individuals with skin types IV to VI, and those living in areas with intense Ultraviolet (UV) radiation. Synonym of melasma are chloasma, black color or black spot[1,2]. Melasma conventional treatments includes eliminating causative agents, coupled with sunscreening, and using hyperpigmenting agents in combination with other therapies. Also, pigmentation disorder is common to those with IV-VI skin type, and people living in intense Ultraviolet environment. However, its pathophysiology is uncertain, as it appears to be present in female hormonal activity, because it occurs more frequently in females than it does in males. Meanwhile, it commonly develops or worsens during pregnancy when using oral contraceptive pills. Indeed, one-half of cases presented were during pregnancy. Additionally, the expression of estrogen receptors appears to be up-regulated in melasma lesions $[3,4]$. The most important factor in its development is the exposure to sunlight. Ultraviolet radiation is known to induce increased production of alpha-melanocyte-stimulating hormone (alpha-MSH), corticotropin, interleukin1(IL-1), and endothelin 1, as they all contributed to increase melanin production by intraepidermal melanocytes. The fibroblasts located in the skin's epidermal layer also contribute to its development. Moreover, overexpression of the tyrosine kinase receptor c-kit and certain stem cell factors have been identified in melasma lesions, which increase melanogenesis[5].Prevalence in Latin women from 
South America was reportedly around 8.8\%, which was high as 40\% population of Southeast Asia. Furthermore, this pigmentation disorder is more common in people with skin types IV-VI, especially Hispanic, Caribbean, and Asian women living in areas with high exposure to ultraviolet light. In Indonesia, women's to men's ratio of the disorder is 24:1 respectively. Also it is commonly seen in childbearing women with sun exposure history. Subsequently, the highest incident recorded was between the age of 30 and 44 years[6]. The human pigmentation system consists of two cells namely, melanocytes and keratinocytes, along with cellular components that interact to form an end product called melanin pigment. Melanocytes are exocrine cells, which are located in the basal layer of the epidermis and the hair bulb matrix. Each melanocyte basal layer is connected through melanocyte dendrites with 36 keratinocytes in the epidermal malphigius layer. This is called epidermal layer melanin unit. Melanocytes produce tyrosinase and melanosomes. Also within, melanocytes produce two melanin subtypes namely, eumelanin and pheomelanin. Tyrosinase plays a role in these two melanin subtypes' formation [7].

\section{Materials and Methods:}

This is an experimental study, in which a cross-sectional with randomized control study was done at Dr. Moewardi General Hospital from June to August 2019. The patients were proficiently grouped based on age, occupation, education, and melasma type. The melanin index measurement uses Mexameter®MX-18 (CourageKhazaka), and for accuracy Melasma Area and Severity Index (MASI) score used. The comparative test was conducted based on Mann-Whitney statistical analysis only when the distribution was irregular. The cream combination used in the experiment includes: phenylethyl-resorcinol $0.1 \%$, lactic acid $0.04 \%$, palmitol tripeptide-5 $0.01 \%$ and retinol $0.01 \%$ as non-hydroquinone cream. Modified Kligman's formula which consist of hydroquinone 2\%, tretinoin 0,05\%, and dexamethasone $0.1 \%$ was used as control. Therefore, the statistical analysis used was the Mann Whitney test and Pearson Chi square.

\section{Results}

Thirty-two patients were examine and divided into two groups. Group A used a cream, containing a combination of non-hydroquinone (phenylethyl-resorcinol, lactic acid, palmitol tripeptide-5, retinol phenylethyl-resorcinol 0.1\%, lactic acid 0.04\%, palmitol tripeptide-5 $0.01 \%$, and retinol 0.01) compared to the modified Kligman's formula (hidrokuinon 2\%, tretinoin 0.05\%, and dexamethasone $0.1 \%$ ) on melasma patients. Age of patients that participated ranged from 20 to 50 years. Based on (Table 1)demographic data, the most age groups were 31-50 years (62.5\%). In group A more patients were found at age $41-50$ years (21.8\%) compared to group B (12.5\%). Among our patients, $6(18.6 \%)$ were housewives, 19 (59\%) were private workers, $1(3.1 \%)$ was a student, and 5 patients (15.5\%) were office workers.

The melanin index in melasma is an indicator for pigmentation assessment, using the Mexameter® MX 18 tool (Courage \& Khazaka electronic GmbH. Cologne, Germany). This tool is a narrow-band reflectance spectrophotometer designed to measure melanin pigmentation based on the absorption of light from the skin. The Mexameter ${ }^{\circledR}$ can show measurements for light absorbed and reflected at red and infrared wavelengths for melanin.Based on (Table 2), a significant difference was found only in the improvement measurement, from baseline to week $8(\mathrm{p}<0.05)$

Based on (Table 3), a significant difference was found on the effect of non-hydoquinone creams at week 2 and week 4 compared to control ( $p<0.05)$, however at week 8 there was no significant correlation in the two groups ( $p>0.05)$. Based on (Table 4). A similar significant difference was also found based on Modified Melasma Area and Severity Index (mMASI) in the two group ( $p<0.05$ ).

\begin{tabular}{|c|c|c|c|c|}
\hline \multicolumn{5}{|c|}{ Table 1: Demographic Data } \\
\hline & & Group A $(n=18)$ & Group B $(n=14)$ & $\mathbf{P}$ \\
\hline \multirow[t]{4}{*}{ Age (years) } & $21-30$ & $3(9.3 \%)$ & $3(9.3 \%)$ & $\mathrm{p}>0.05$ \\
\hline & $31-40$ & $5(15.6 \%)$ & $4(12.5 \%)$ & \\
\hline & $41-50$ & $7(21.8 \%)$ & $4(12.5 \%)$ & \\
\hline & $>50$ & $3(9.3 \%)$ & $3(9.3 \%)$ & \\
\hline \multirow[t]{5}{*}{ Occupation } & Government & $3(9.3 \%)$ & $2(6.2 \%)$ & $\mathrm{p}>0.05$ \\
\hline & Private & $12(37.5 \%)$ & $7(21.5 \%)$ & \\
\hline & Housewife & $2(6.2 \%)$ & $4(12.4 \%)$ & \\
\hline & Farmer & $1(3.1 \%)$ & - & \\
\hline & Student & - & $1(3.1 \%)$ & \\
\hline \multirow{3}{*}{ Melasma Types } & Epidermal & $4(12.4 \%)$ & $2(6.4 \%)$ & \multirow{3}{*}{$\mathrm{p}>0.05$} \\
\hline & Dermal & $2(6.4 \%)$ & $3(9.3 \%)$ & \\
\hline & Campuran & $12(37.5 \%)$ & $9(27.9 \%)$ & \\
\hline
\end{tabular}




\begin{tabular}{|c|c|c|c|}
\hline \multicolumn{4}{|c|}{ Table 2: Melanin index using non-hydroquinone cream and modified Kligman's formula cream } \\
\hline Time of visit & Group A (Mean) & Group B (Mean) & p value \\
\hline V0-V2 & 1.1261 & 3.3971 & 0.920 \\
V0-V3 & 1.6822 & 7.3500 & 0.17 \\
V0-V4 & 2.1300 & 6.2464 & 0.54 \\
V0-V5 & 0.8394 & 11.7221 & 0.04 \\
\hline
\end{tabular}

Table 3: Correlation of therapeuctical effect using non-hydoquinone cream and modified Kligman's formula cream (Pearson Chi square)

\begin{tabular}{|c|c|c|}
\hline Time of visit & Coefficient contingency & p value \\
\hline V0-V2 & .409 & 0.04 \\
V0-V3 & .285 & 0.243 \\
V0-V4 & .449 & 0.044 \\
V0-V5 & .316 & 0.05 \\
\hline
\end{tabular}

\begin{tabular}{|l|l|l|l|}
\hline \multicolumn{3}{|c|}{ Table 4: Modified MASI score } & p value \\
\hline Time of visit & Group A (Mean) & Group B (Mean) & 0.034 \\
\hline V0-V2 & 3.333 & 2.4500 & 0.014 \\
V0-V3 & 3.1278 & 2.1785 & 0.104 \\
V0-V4 & 2.7056 & 2.1071 & 0.345 \\
V0-V5 & 5.399 & 4.890 & \\
\hline
\end{tabular}

\section{Discussion}

In group $A$, more patients were found at age 41-50 years (21.8\%) compared to group B (12.5\%). Among our patients, $6(18.6 \%)$ were housewives, $19(59 \%)$ were private workers, 1 (3.1\%) was student, and 5 patients $(15.5 \%)$ were office workers. The incidence of melasma increases among individuals with outdoor activities as sun exposure aggravates its effect, however, housewives with less sun exposure develop other factors inducing melasma pathophysiology, such as hormonal influence. In addition, $50 \%$ and $18.8 \%$ patients had mixed and epidermal melasma respectively. Wood's lamp examination is helpful in classifying melasma into epidermal, dermal, mixed, and indeterminate lesions accentuating under Wood's lamp. Consequently, epidermal melasma responds to local treatment, while dermal and mixed are less or non-responsive. But Wood's lamp examination is not completely reliable in predicting response to treatment especially dark-skinned populations [8].

Retinoids reduce hyperpigmentation by stimulating melanin, which is released through increased epidermal turnover. also by reducing the following, melanosomes transfer from melanocytes to keratinocytes, the duration of melanosomes on keratinocytes, and melanogenesis through inhibition of tyrosinase transcription [9]. Retinoids and its derivatives were reportedly effective in treating melasma, with some side effects that often arise, such as irritation or redness and peeling on the area that was smeared, and sometimes hyperpigmentation as well [10]. Although retinoid acid takes longer than non-hydroquinone to elicit a response in melasma (clinically, an enlightening effect appears after 24 weeks), when it was combined with lactic acid (7\%) or ascorbic acid (10\%) its effect was not only good but also fast [8]. Phenylethyl resorcinol is an antioxidant that is considered effective in influencing the formation of pigmentation, and therefore can brighten the skin [11]. According to research published by Symrise, phenylethyl resorcinol was proved to be more effective than B-Arbutin for hair lightening, and also for exposed skin lightening. Its $0.5 \%$ concentration is more effective than $0.1 \%$ kojic acid concentration [12]. Other forms of resorcinol derivatives such as butyl resorcinol are also able to inhibit the tyrosinase enzyme, which is useful in melasma therapy [13].

\section{Conclusion}

A significant difference was obtained in melanin index with nonhydoquinone cream especially at week 4 of visit, while in group B, using modified Kligman's formula, a significant difference also was obtained as seen in week 2 , and 4 of visit. 


\section{References}

1. Pandya AG, Hynan LS, Bhore R, Riley FC, Guevara IL, Grimes P. Reliability Assessment and Validation of the Melasma Area and Severity Index (MASI) and a New Modified MASI Scoring Method. J Am Acad Dermatol. 2011;64(1):80-88.

2. Lapeere H, Boone B, Schepper SD, Verhaghe E, Ongenae K, Van Gelle $\mathrm{N}$, et al. Hypomelanoses \&Hypermelanoses. In : Goldsmith LA, KatzSI, Gilchrest BA, Paller AS, Leffel D \& Wolff K.Fitz Patrick's Dermatology in General Medicine. $8^{\text {th }}$ edition. New York: McGraw-Hill. 2012:804-826.

3. Jang YH, Lee JY, Kang HY, Lee ES, Kim YC. Oestrogen and Progesterone Receptor Expression in Melasma: An Immunohistochemical Analysis. J Eur Acad Dermatol Venereol. 2010;24(11):1312-1316.

4. DamevskaK.New Aspects of Melasma. Serbian J Dermatology Venereol. 2014;6(1):5-18.

5. Ortonne JP, Arellano I, Berneburg M, Cestari T, Chan H, Grimes P, et al,. A Global Survey of the Role of Ultraviolet Radiation and Hormonal Influences in the Development of Melasma. J Eur Acad Dermatol Venereol. 2009;23(11):1254-1262.
6. Kang S, Sober AJ. Disturbance of melanin pigmentation. In: Moschella SL, Hurley HJ. Editor. Dermatology. $3^{\text {rd }}$ ed. London: WB Saunders. 1992;1321-1374.

7. Jimbow K, Minamitsuji Y. Topical Therapies for Melasma and Disorders of Hyperpigmentation. Dermatol Ther. 2001;14:35-45.

8. Aswanonda P, Tyalo CR. Woods Light in Dermatology. Int J Dermatol. 1999;38:801-807.

9. Khanna N, Rasool S.Facial Melanoses:Indian perspective.Indian J Dermatol Venereol Leprol. 2011;77(5):552-564.

10. Ebanks JP, Wickett, RR, Boissy RE. Mechanisms Regulating Skin Pigmentation: The rise and Fall of Complexion Coloration. Int J Mol Sci. 2009;10(9):4066-4087.

11. GoldMH \& Biron JA.Retrospective Study on the Clinical Presentation and Treatment Free-Skin Brightening Cream in Patients with Melasma. J Cosmec Dermatol.2011;10:189-196.

12.Zeinker S. Bleach Peeling for Melasma : An Effective Approachto Treatment. JAN. 2018;7(3):136-143.

13. Kaliterna D, Zuzul K, Kovacevic I. Melasma-Review of Current Treatment Modalities and Efficacy Assessment of a New ResorcinolBased Topical Formulation. J ClinCosmetDermatol. 2017;1(3):1-4. 